\title{
A Universal Scaling Law for the Strength of Metal Micropillars and Nanowires
}

R. Dou and B. Derby

\begin{abstract}
The yield strength of sub-micron single crystal metal pillars and wires increases with decreasing pillar diameter. Here we show that the yield stress (resolved onto a slip system), $\sigma_{r s s}$, scaled by shear modulus, $\mu$, and the diameter, $d$, scaled by Burgers vector, $b$, shows the following universal correlation: $\sigma_{r s s} / \mu=A(d / b)^{m}$; for fcc metals $A=0.71$ and $m=-0.66$. Data for Mo and a Mo alloy are found to approximately obey the fcc correlation, despite having a different crystal structure.
\end{abstract}

Scripta Materialia 61 (2009) 524-527

doi:10.1016/j.scriptamat.2009.05.012 
Uchic et al first reported an anomalous increase in the strength of single crystal metal pillars with diameter $<1 \mu \mathrm{m}$, produced by focussed ion beam (FIB) machining and tested in compression.[1] There have been large number of subsequent studies on the strength of FIB machined single crystal micropillars (and smaller single crystal nanowires fabricated by templated electrodeposition) from a range of face centred cubic (fcc) structure metals including $\mathrm{Au},[2-6] \mathrm{Ni},[1,7,8] \mathrm{Cu},[9,10]$ and $\mathrm{Al} .[11]$ In most cases the deformation of individual micropillars follows an erratic stress/strain history, with deformation occurring in bursts of strain at almost constant stress interspersed by regions of elastic deformation. In these samples deformation appears to be highly localised with clearly visible shear offsets along the deformed pillar. In a few cases deformation post yield showed a continuous increase in deformation stress with increasing plastic strain, analogous to the deformation behaviour of polycrystals. Table 1 presents a summary of these previous studies. This report is confined to an examination of compression experiments on small pillar structures and will not consider studies where similar size structures have been tested in bend, $[9,14]$ nor will it concern itself with the considerable body of data on the deformation of nanoporous metals [1519]. We have limited ourselves to simple compression loading because these other structures and tests introduce strain gradients during deformation, which generates a well known influence of structural scale on deformation stress.

We reviewed the size dependence of the compression strength of gold micropillars earlier [6] and reported a trend of increasing yield stress, $\sigma_{Y}$, with decreasing pillar diameter, $d$, which can be described by the empirical relation: 
where $\sigma_{o}$ is a scale independent yield stress, and $A$ and $m$ are empirical constants; for gold micropillars $m \approx-0.6$. It is more instructive to resolve the yield onto the appropriate slip system $\{111\}<110>$ that shows the lowest resolved shear stress, $\sigma_{r s s}$. This is obtained by multiplying the measured stress by the appropriate Schmid factor (Table 1). Figure 1 shows $\sigma_{r s s}$ for Au micropillars plotted as a function of diameter, along with data for Ni. Both metals show the same power law relation for $\sigma_{r s s}$ as equation 1 , with $m=-0.66$ for $\mathrm{Au}$ and $m=-0.57$ for Ni.

There is no consensus for the mechanism that leads to the observed influence of pillar diameter on strength. At small length scales, conventional mechanisms for the generation of dislocations are severely constrained by the small dimensions of the specimens, which either physically limit the length of dislocation segments available for dislocation multiplication or remove mobile dislocations through the close proximity of free surfaces. [3] Transmission electron microscopy (TEM) observations have found low dislocation densities in gold columns $(d<100 \mathrm{~nm})$ deformed to strains in excess of $30 \%$ [6]. Shan et al observed a decrease in dislocation density during in situ TEM deformation of a Ni micropillar. [20] However, Frick et al [8] found significant dislocation densities in deformed Ni micropillars. Uchic et al have explored mechanisms that assume a sparse distribution of dislocation sources with dislocation segment length controlled by the micropillar or ligament diameter. [21,22] Although this can explain a number of features observed in the deformation of pillars, it does not predict the exponent of the size dependence of yield stress. There has been other work 
using molecular dynamics simulation to predict the nucleation of dislocations during deformation. Again these predict some of the features of micropillar deformation but do not yet give adequate quantitative predictions.[23,24]

We assume that the deformation of micropillars is controlled by dislocation motion. Note that mechanisms of strengthening related to the removal of mobile dislocations still require continuous generation of new dislocations from unspecified sources. In which case, potential strengthening mechanisms will be governed by an interaction of the dislocations with some feature of the micropillar. Hence, the controlling physical property will be the dislocation line tension. This is determined by its Burgers vector and the elastic modulus of the material. In figure 2 we present the data from figure 1 with $\sigma_{r s s}$ normalised by the material's single crystal shear modulus (resolved onto the slip plane and along the slip direction), $\mu$, and the pillar diameter, $d$, normalised by the Burgers vector of the dominant slip system, $b$. In addition to the data for $\mathrm{Au}$ and $\mathrm{Ni}$ single crystal micro pillars we also include data for the compressive strength of micropillars fabricated from $\mathrm{Cu}[9,10]$ and $\mathrm{Al}[11]$. A similar plot was recently presented by Uchic et al [25], however this did not normalise the column diameter but instead reduced the stress axis to a notional length scale using a reference Burgers vector of Ni. We believe the normalisation scheme we have present here provides a more intuitive representation of the universal behaviour seen with micropillar deformation.

In figure 2 , the strength as a function of pillar diameter for $\mathrm{Al}, \mathrm{Au}$ and $\mathrm{Ni}$ clusters tightly around a common linear trend. The data for $\mathrm{Cu}[9,10]$ is separated from the rest 
of the fcc metals, although it shows a similar trend in its behaviour. There are a number of possible reasons for this apparent discrepancy seen with the $\mathrm{Cu}$ data:

1) The data has come from two publications from the same laboratory and thus might include common systematic differences in procedure or analysis.

2) The $\mathrm{Cu}$ data is unique in not displaying bursts of strain interspersed with elastic deformation but instead showing uniform hardening (Table 1). This is not a function of the orientation of the $\mathrm{Cu}$ pillars because both $\mathrm{Au}$ and $\mathrm{Cu}$ micropillars have similar orientations in the published data.

3) The $\mathrm{Cu}$ data that shows the greatest deviation from the other fcc metals,[9] was measured at a plastic strain of $20 \%$, much greater than the other data in Table 1 and coupled with the marked strain hardening could lead to a larger reported stress. We also note that these specimens had been FIB machined with a square cross-section (rather than circular) and with the lowest aspect ratio.

The solid line in figure 2 is given by the relation

$$
\frac{\sigma_{c r s s}}{\mu}=A\left(\frac{d}{b}\right)^{m}
$$

with the constant $A=0.71$ and the exponent $m=-0.66$ determined by a regression fit to the data obtained from $\mathrm{Al}, \mathrm{Au}$ and Ni micropillars.

Figure 2 presents evidence for a strong universal correlation between the strength of fcc metal micropillars and their diameter, using an appropriate normalisation procedure. There is data in the literature for the strength of micropillars obtained from bcc metals 
in the form of elemental Mo and a Mo-Nb-Al alloy (Table 3).[26-28] In figure 3 we plot the data obtained from FIB machined Mo micropillars[26] using the same normalisation as used with the fcc metals, assuming slip along the $\{110\}<111>$ slip system. We also plot the strength for Mo alloy micropillars produced by the deep etching of fibrous eutectics (Mo2a in figure 3) and the eutectic fibres pre-strained prior to testing (Mo2b and Mo2c).[27,28] In the absence of published data we have used the Burgers vector of pure Mo for normalising the Mo alloy pillar diameters, however we have used published data for the resolved shear modulus.[29] The dashed line in figure 3 is the regression fit to the data from $\mathrm{Al}, \mathrm{Au}$ and $\mathrm{Ni}$ micropillars obtained from figure 2.

A strong correlation between normalised micropillar strength and diameter is only seen with FIB machined Mo pillars (Mo1 in figure 3). It is not seen in highly perfect, Mo single crystal pillars produced by dissolution from eutectics (Mo2a).[27] These are reported to be dislocation free prior to compression and show a high yield stress followed by a significant drop in flow stress.[27,28] This behaviour is similar to that of dislocation-free metal whiskers tested in tension [30,31]. In which case the high initial yield stress is required to nucleate dislocations and the lower subsequent flow stress occurs because a number of dislocation sources are now active following dislocation interactions and further plastic deformation no longer requires the homogenous nucleation of dislocations. To test this hypothesis, Bei et al measured the compressive strength of Mo micropillars produced by deep etching eutectic microstructures after plastic pre-strains of $4 \%$ and $11 \%$ as well as in the undeformed state[27] and it is data from these pre-strained pillars (Mo2b and Mo2c respectively) that lies close to the scaling trend seen in figures 2 and 3. The pre-strained eutectic pillars of the Mo alloy 
show a very large degree of scatter and do not show a clear dependence of strength on pillar diameter; although the mean values of the data for the $4 \%$ prestrained Mo (Mo2b) may follow the fcc trend line. Viewing the data for FIB machined Mo and the prestrained Mo alloy micropillars as a whole, there appears to be a size effect that is very similar to that found with $\mathrm{Al}, \mathrm{Au}$ and $\mathrm{Ni}$ (dashed line in fig. 3), at least when $d / b<10^{3}$; at larger diameters the data shows too much scatter to determine conclusively any size effect.

A single data point is shown in figure 3 from one study of the compression deformation of a GaAs micropillar produced by FIB.[32] This data does not sit on the trend line. However, the intrinsic critical resolved yield stress of GaAs at room temperature has been measured as $600-800 \mathrm{MPa}[33]$ or $0.015<\sigma_{\mathrm{rss}} / \mu<0.021$ and this is approximately the value found with the micropillar, indicating no influence of specimen size. However, little can be deduced from this single data point other than it lies intermediate between the "perfect crystal" behaviour of the dislocation free eutectic Mo alloy data and the data from the scale dependent materials.

This survey of the experimental data for the deformation of metal micropillars fabricated by FIB (and templated electrodeposition) has found what appears to be a universal scaled (or normalised) behaviour for the plastic flow stress of metal micropillars, that applies when discontinuous localised plastic deformation is observed for fcc metals and possibly also for bcc metals. The resolved shear stress for plastic flow is related to the pillar diameter, material shear modulus and the Burgers' vector of 
the active slip system with the following empirical relation identified for data from $\mathrm{Au}$, $\mathrm{Ni}$ and $\mathrm{Al}$ :

$$
\frac{\sigma_{c r s s}}{\mu}=0.71\left(\frac{d}{b}\right)^{-0.66}
$$

The data for Mo, which has a different crystal structure is also shown to lie very close to this trend line. We hypothesize that the deformation mechanisms in these small micropillars are controlled by conventional dislocation processes with heterogenous nucleation of dislocations from surface imperfections or sparsely distributed sources such as hypothesised by Parthasarathy et al. [22] and recently reported by Oh et al. [34]. Further work is needed to determine the precise mechanism for this behaviour and to identify differences (e.g. in the value of the exponent $m$ ) between materials with different crystal structure. It is unclear why perfect, dislocation-free metal whiskers and Mo pillars isolated by etching from eutectics do not show this behaviour.

\section{$\underline{\text { References }}$}

[1] M.D. Uchic, D.M. Dimiduk J.N. Florando, W.D. Nix, Science 305, (2004) 986.

[2] J.R. Greer, W.C. Oliver, W.D. Nix, Acta Materialia 53, (2005) 1821.

[3] J.R. Greer, W. D. Nix, Phys. Rev. B 73, (2006) 245410.

[4] C.A. Volkert, E.T. Lilleodden, Philos. Mag. 86, (2006) 5567.

[5] R. Maass, D. Grolimund, S.Van Petegem, M. Willimann, M. Jensen, H. Van

Swygenhoven, T. Lehnert, M.A.M. Gijs, C.A. Volkert, E.T. Lilleodden, R. Schwaiger, Appl. Phys. Lett. 89, (2006) 151905. 
[7] D.M. Dimiduk, M.D. Uchic, T.A. Parthasarathy, Acta Mater. 53, (2005) 4065.

[8] C.P. Frick, B.G. Clark, S. Orso, A.S. Schneider, E. Arzt, Mater. Sci. Eng. A 489, (2008) 319.

[9] G. Dehm, C. Motz, C. Scheu, H. Clemens, P.H. Mayrhofer, C. Mitterer, Adv. Eng. Mater. 8, (2006) 1119.

[10] D. Kiener, C. Motz, T. Schöberl, M. Jenko, G. Dehm, J. Mater. Sci. (2008) 43, 2503,

[11] K.S. Ng, A.H.W. Ngan, Acta Mater. 56, (2008) 1712.

[12] A.G. Every, A.K. McCurdy, Landolt-Börnstein: Numerical Data and Functional Relationships in Science and Technology: Condensed Matter, Vol. 29a, Springer, Berlin, Germany, 1992.

[13] G. Sachs, Z. Verin Dtsch. Ing. 72, (1923) 734.

[14] B. Wu, A. Heidelberg, J.J. Boland, Nature Mater. 4, (2005) 525.

[15] J. Biener, A.M. Hodge, A.V. Hamza, L.M. Hsiung, J.H. Satcher, J. Appl. Phys. 97, (2005) 024301.

[16] C.A. Volkert, E.T. Lilleodden, D. Kramer, J. Weissmuller, Appl. Phys. Lett. 89, (2006) 061920.

[17] D. Lee, X. Wei, X. Chen, M. Zhao, S.C. Jun, J. Hone, E.G. Herbert, W.C.

Oliver, J.W. Kysar, Scripta Mater. 56, (2007) 437.

[18] M. Hakamada, M. Mabuchi, Scripta Mater. 56, (2007) 1003.

[19] A.M. Hodge, J. Biener, J.R. Hayes, P.M. Bythrow, C.A. Volkert, A.V. Hamza, Acta Mater. 55, (2007) 1343. 
[20] Z.W. Shan, R.K. Mishra, S.A.S. Asif, O.L. Warren, A.M. Minor, Nature Mater. 7, (2008) 115.

[21] S.I. Rao, D.M. Dimiduk, M. Tang, T.A. Parthasarathy, M.D. Uchic, C.

Woodward. C., Philos. Mag. 87, (2007) 4777.

[22] T.A. Parthasarathy, S.I. Rao, D.M. Dimiduk, M.D. Uchic, D.R. Trinkle, Scripta Mater. 56, (2007) 313.

[23] E. Rabkin, H.S. Nam, D.J. Srolovitz, Acta Mater. 55, (2007) 2085.

[24] E. Rabkin, D.J. Srolovitz, Nano Lett. 7, (2007) 101.

[25] M.D. Uchic, P.A. Shade, D.M. Dimiduk, J. Metals, 61(3), (2009) 36.

[26] J.Y. Kim, J.R. Greer, Appl. Phys. Lett. 93, (2008) 101916.

[27] H. Bei, S. Shim, E.P. George, M.K. Miller, E.G. Herbert, G.M. Pharr, Scripta Mater. 57, (2007) 397.

[28] H. Bei, S. Shim, G.M. Pharr, E.P. George, Acta Mater. 56, (2008) 4762.

[29] H. Bei, Y.F. Gao, S. Shim, E.P. George, G.M. Pharr, Phys. Rev. B, 77, (2008) 060103(R).

[30] S.S. Brenner, J. Appl.Phys. 27, (1956) 1484.

[31] S.S. Brenner, J. Appl.Phys. 28, (1957) 1023.

[32] J. Michler, K. Wasmer, S. Meier, and F. Östlunda, Appl. Phys. Lett. 90, (2007) 043123.

[33] Y. Androussi, G. Vanderschaeve, Philos. Mag. A 59, (1989) 1189.

[34] S.H. Oh, M. Legros, D. Kieber and G. Dehm, Nature Mater. 8, (2009) 95. 


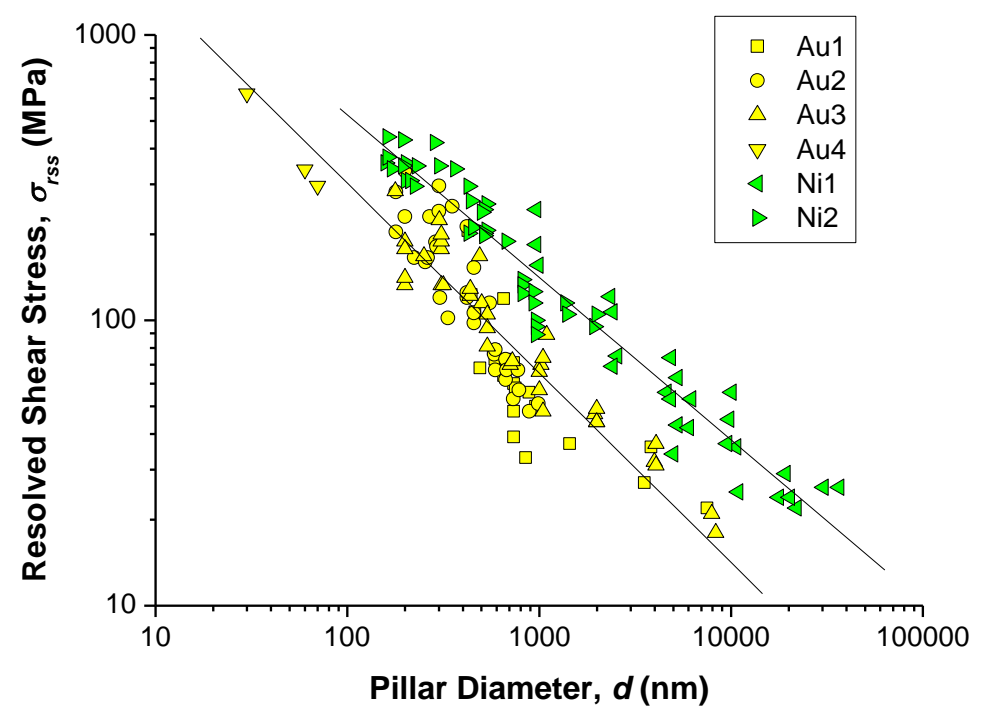

Figure 1 Resolved shears stress for plastic deformation plotted against pillar diameter for a range of single crystal micropillars fabricated from $\mathrm{Au}$ and Ni. Lines indicate an empirical exponential fit to the combined data for each metal. See Table 1 for source references. 


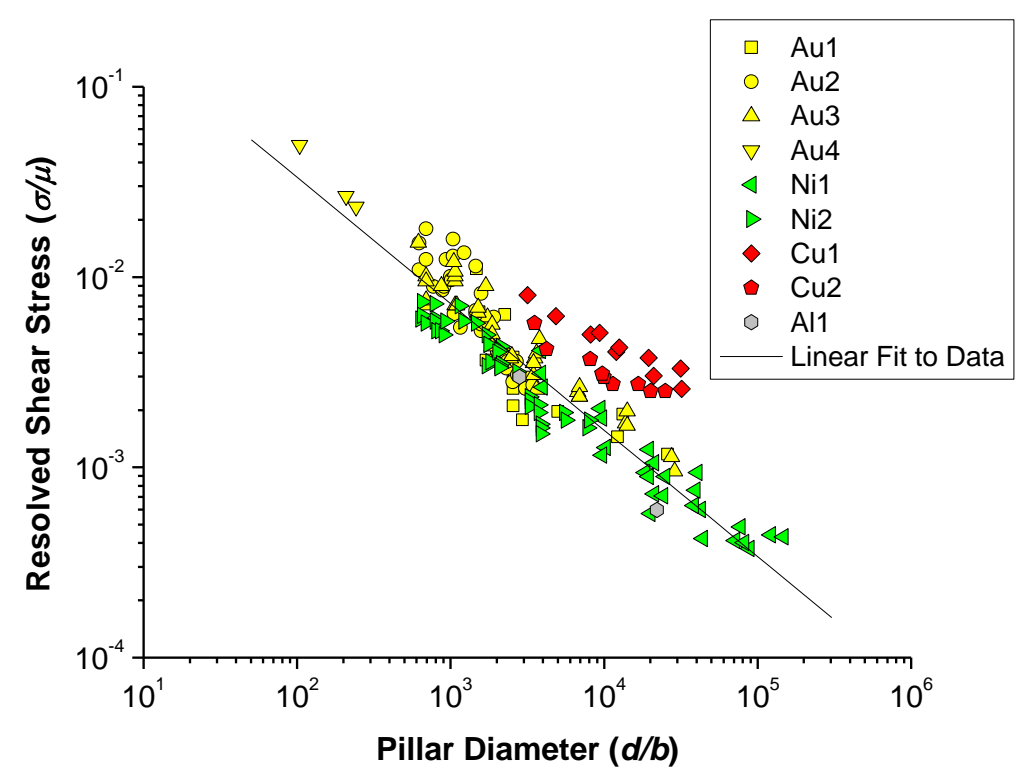

Figure 2 Resolved shear stress for micropillar deformation of fcc metals, normalised by shear modulus (resolved onto the $\{111\}<110>$ slip system), plotted against pillar diameter, normalised by Burgers vector. Solid line shows linear regression to $\mathrm{Au}, \mathrm{Ni}$ and Al data. See Table 1 for source references. 


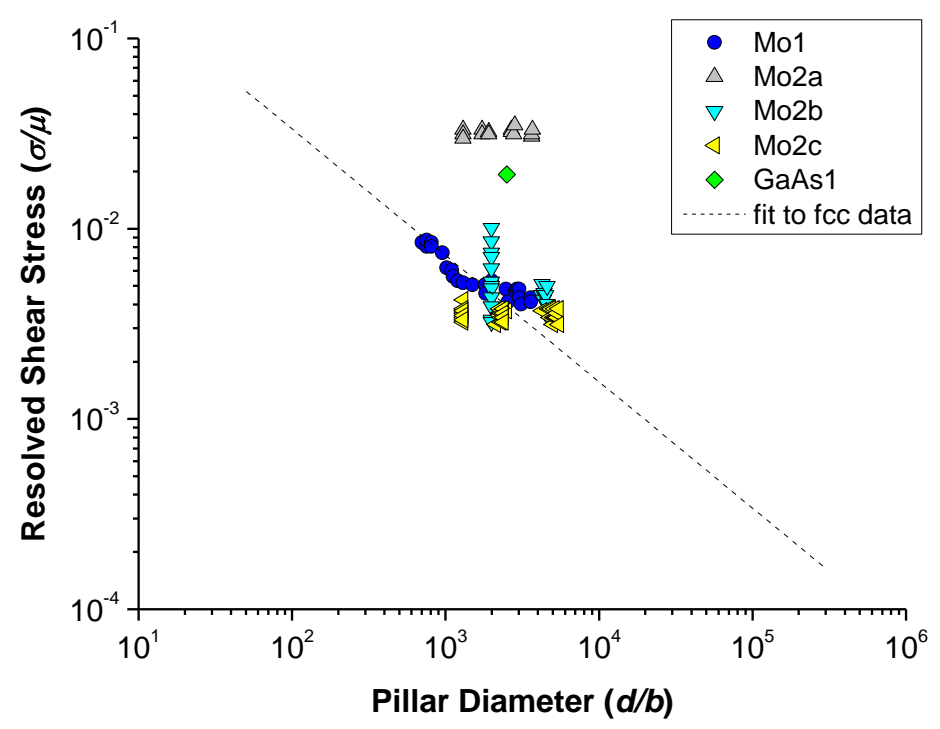

Figure 3 Resolved shear stress for micropillar deformation, normalised by shear modulus (resolved on to $\{110\}<111>$ slip system for Mo and $\{111\}<110>$ for GaAs), plotted against pillar diameter, normalised by Burgers vector. Dashed line indicates regression line obtained from fcc data in figure 2. See Table 2 for source references. 
Table 1 Summary of information concerning published data on the compression strength of fcc metal micropillars.

\begin{tabular}{|c|c|c|c|c|c|c|c|c|c|c|c|}
\hline Material & Sample & $\begin{array}{c}\text { Fabrication } \\
\text { Route }\end{array}$ & $\begin{array}{c}\text { Diameter } \\
(\mathbf{n m})\end{array}$ & $\begin{array}{l}\text { Aspect } \\
\text { Ratio }\end{array}$ & $\begin{array}{c}\text { Section } \\
\text { Shape }\end{array}$ & Orientation & $\begin{array}{l}\text { Schmid } \\
\text { Factor }\end{array}$ & $\begin{array}{l}\text { Shear Modulus } \\
\text { on Slip Plane } \\
(\text { GPa })^{\mathrm{a}}\end{array}$ & Strain & $\begin{array}{c}\text { Flow } \\
\text { Behaviour }\end{array}$ & Ref. \\
\hline$A u$ & $A u 1$ & FIB & $400-7000$ & $3: 1$ & Circular & $\langle 001\rangle$ & 0.41 & 18.7 & $10 \%$ & Strain bursts & [2] \\
\hline$\overline{A u}$ & $A u 2$ & FIB & $200-1000$ & $>3: 1$ & Circular & $\langle 001\rangle$ & 0.41 & 18.7 & $10 \%$ & Strain bursts & [3] \\
\hline$A u$ & $A u 3$ & FIB & $180-8000$ & $1.5: 1-4: 1$ & Circular & $\begin{array}{c}3 \text { different } \\
\text { grains }\end{array}$ & $0.48^{\mathrm{b}}$ & 18.7 & $5 \%$ & Strain bursts & [4] \\
\hline$A u$ & $A u 4$ & $\begin{array}{c}\text { Electro - } \\
\text { deposition }\end{array}$ & $30-70$ & $>5: 1$ & Circular & $\begin{array}{c}\text { Random } \\
\text { orientation }\end{array}$ & $0.45^{\mathrm{c}}$ & 18.7 & $10 \%$ & $\begin{array}{c}\text { No work } \\
\text { hardening }\end{array}$ & [6] \\
\hline$N i$ & $\mathrm{Nil}$ & FIB & $\begin{array}{l}1000- \\
40000\end{array}$ & $2: 1-3: 1$ & Circular & $\langle 269\rangle$ & 0.48 & 59.3 & $1 \%$ & Strain bursts. & [7] \\
\hline $\mathrm{Ni}$ & $\mathrm{Ni2}$ & FIB & $200-4500$ & $2: 1-7: 1$ & Circular & $\langle 111\rangle$ & 0.27 & 59.3 & $3 \%$ & Strain bursts & [8] \\
\hline$C u$ & $\mathrm{Cu} 1$ & FIB & $1000-8000$ & $1.5: 1-2: 1$ & Square & $\langle 111\rangle$ & 0.27 & 30.5 & $20 \%$ & $\begin{array}{l}\text { Continuous } \\
\text { deformation }\end{array}$ & [9] \\
\hline$C u$ & $\mathrm{Cu} 2$ & FIB & $900-6400$ & $>2.5$ & Square & $\langle 001\rangle$ & 0.41 & 30.5 & $10 \%$ & $\begin{array}{l}\text { Continuous } \\
\text { deformation }\end{array}$ & [10] \\
\hline$A l$ & All & FIB & $700-6500$ & $4: 1$ & Circular & $\langle 315\rangle$ & 0.47 & 24.5 & $10 \%$ & Strain bursts & [11] \\
\hline
\end{tabular}

${ }^{a}$ Calculated from single crystal elastic constant data in Ref. [12]

${ }^{b}$ Three different $\mathrm{Au}$ grains selected with orientations giving the same Schmid factor.

${ }^{\mathrm{c}}$ Randomly oriented micropillars, Sachs factor used as an average Schmid factor.[13] 
Table 2 Summary of information concerning published data on the compression strength of Mo and Mo alloy micropillars..

\begin{tabular}{|c|c|c|c|c|c|c|c|c|c|c|c|}
\hline Material & Sample & $\begin{array}{c}\text { Fabrication } \\
\text { Route }\end{array}$ & $\begin{array}{l}\text { Diameter } \\
(\mathbf{n m})\end{array}$ & $\begin{array}{l}\text { Aspect } \\
\text { Ratio }\end{array}$ & $\begin{array}{c}\text { Section } \\
\text { Shape }\end{array}$ & Orientation & $\begin{array}{l}\text { Schmid } \\
\text { Factor }\end{array}$ & $\begin{array}{l}\text { Shear Modulus } \\
\text { on Slip Plane } \\
(\mathbf{G P a})^{\mathrm{a}}\end{array}$ & Strain & $\begin{array}{c}\text { Flow } \\
\text { Behaviour }\end{array}$ & Ref. \\
\hline Mo & Mol & FIB & $200-1000$ & $3: 1$ & Circular & $\langle 001\rangle$ & 0.41 & 133.7 & $10 \%$ & $\begin{array}{l}\text { Strain } \\
\text { bursts }\end{array}$ & [26] \\
\hline Mo alloy & Mo2 & Eutectic & $300-1400$ & $2.5: 1-3: 1$ & Square & $<001\rangle$ & 0.41 & $120.3^{b}$ & $10 \%$ & $\begin{array}{l}\text { Strain } \\
\text { bursts }^{\mathrm{c}}\end{array}$ & {$[27,28]$} \\
\hline GaAs & GaAsl & FIB & 1000 & 3.2 & Circular & $\langle 001\rangle$ & 0.41 & 38.3 & $7 \%$ & $\begin{array}{l}\text { Strain } \\
\text { bursts }\end{array}$ & [32] \\
\hline
\end{tabular}

${ }^{a}$ Calculated from single crystal elastic constant data in Ref. [12].

${ }^{\mathrm{b}}$ Stated in Ref. [29].

${ }^{c}$ Strain bursts only seen in pre-strained specimens. 